\title{
Recent Developments in the Use of Glyconanoparticles and Related Quantum Dots for the Detection of Lectins, Viruses, Bacteria and Cancer Cells
}

OPEN ACCESS

Edited by: Cristina Nativi,

University of Florence, Italy

Reviewed by: Linghui Qian,

Zhejiang University, China Marco Marradi, University of Florence, Italy

${ }^{*}$ Correspondence: Robert A. Field rob.field@icenidiagnostics.com

Specialty section: This article was submitted to Chemical Biology, a section of the journa

Frontiers in Chemistry

Received: 16 February 2021 Accepted: 05 July 2021

Published: 19 July 2021

Citation:

Hernando PJ, Dedola S, Marín MJ and Field RA (2021) Recent Developments in the Use of Glyconanoparticles and Related Quantum Dots for the Detection of Lectins, Viruses, Bacteria and Cancer Cells.

Front. Chem. 9:668509. doi: $10.3389 /$ fchem.2021.668509

\begin{abstract}
Pedro J. Hernando ${ }^{1,2}$, Simone Dedola ${ }^{1}$, María J. Marin ${ }^{3}$ and Robert A. Field ${ }^{1,4 *}$
${ }^{1}$ Iceni Diagnostics Ltd., Norwich Research Park Innovation Centre, Norwich, United Kingdom, ${ }^{2}$ Quadram Institute Bioscience, Norwich, United Kingdom, ${ }^{3}$ School of Chemistry, University of East Anglia, Norwich, United Kingdom, ${ }^{4}$ Department of Chemistry, Manchester Institute of Biotechnology, University of Manchester, Manchester, United Kingdom
\end{abstract}

Carbohydrate-coated nanoparticles - glyconanoparticles - are finding increased interest as tools in biomedicine. This compilation, mainly covering the past five years, comprises the use of gold, silver and ferrite (magnetic) nanoparticles, silicon-based and cadmiumbased quantum dots. Applications in the detection of lectins/protein toxins, viruses and bacteria are covered, as well as advances in detection of cancer cells. The role of the carbohydrate moieties in stabilising nanoparticles and providing selectivity in bioassays is discussed, the issue of cytotoxicity encountered in some systems, especially semiconductor quantum dots, is also considered. Efforts to overcome the latter problem by using other types of nanoparticles, based on gold or silicon, are also presented.

Keywords: glyconanoparticles, gold nanoparticles, rapid diagnostics, pathogen detection, cancer imaging, glycobiology

\section{INTRODUCTION}

The use of nanoparticles (NPs) as biomedical tools has developed at pace in recent years, with NPs functionalised with carbohydrates (glyconanoparticles) emerging in diagnostics and cell imaging. Since the first report of glyconanoparticles (de la Fuente et al., 2001), interest in these materials has risen considerably. The main approaches to the preparation and early applications of glyconanoparticles have been reviewed previously (de la Fuente and Penadés, 2006; Marradi et al., 2013; Chen et al., 2014), as has the application of glyconanoparticles in biomedicine (Dosekova et al., 2017; Kveton et al., 2020), the use of magnetic glyconanoparticles in biosensing (Fratila et al., 2016), and glyconanoparticles for the detection of cancer cells and the early diagnosis of cancer (Hockl et al., 2016; Torres-Pérez et al., 2020).

The first examples of glyconanoparticles focused on gold, silver, and iron oxide systems. The impact of the size and shape of the nanoparticle, as well as the density of carbohydrates on the surface of the nanoparticle and the importance of the tether employed for the functionalisation, have been studied and reviewed (Compostella et al., 2017). Key conclusions are that, for certain applications, nanoparticles with larger size present flatter surfaces, enhancing carbohydrate-target interactions (Chien et al., 2008); the shape of the particle (rods vs. spheres) can also impact on the detection limit of Escherichia coli-glyconanoparticle interactions, for instance (Chaudhary et al., 2015). 


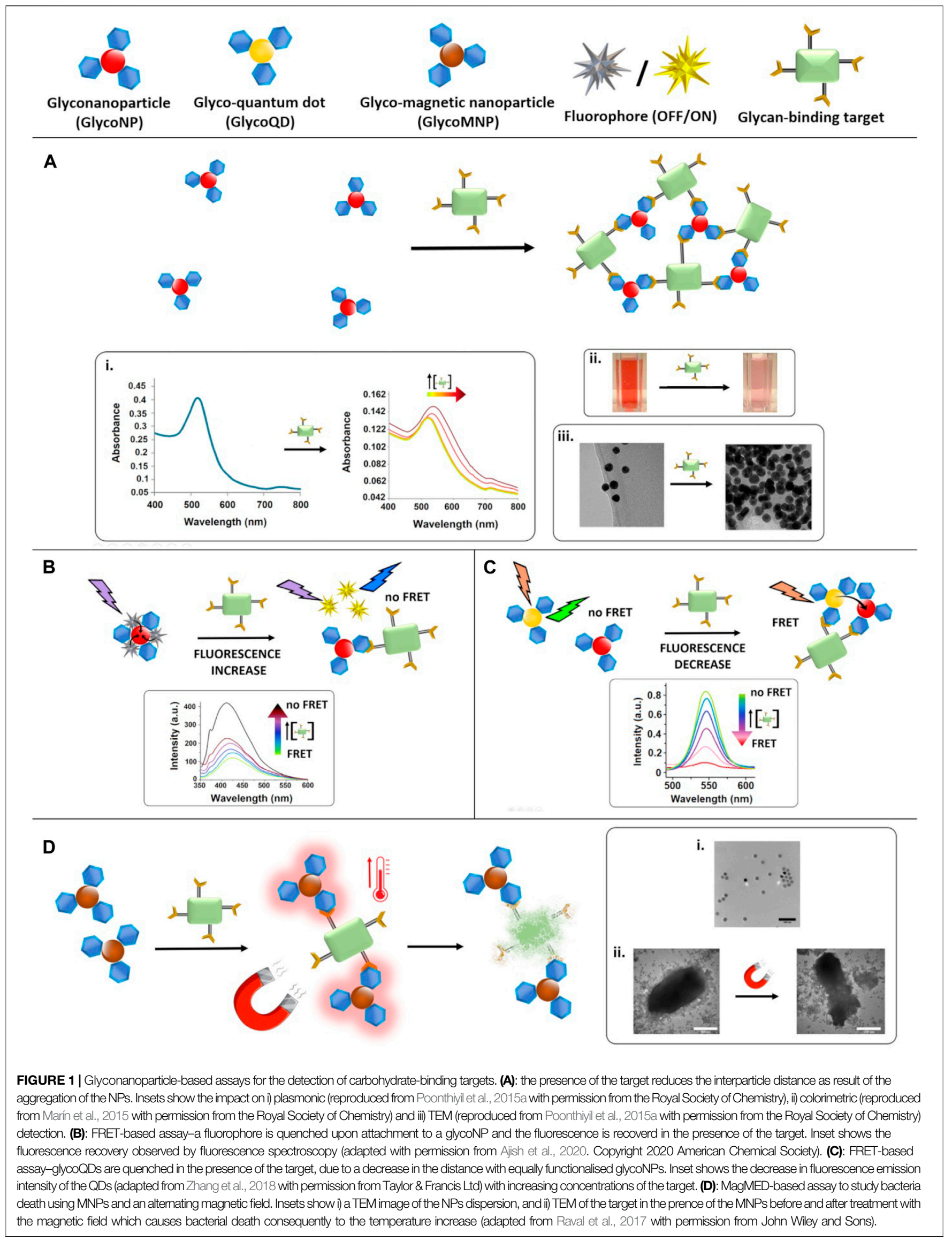


TABLE 1 | GlycoNPs and QDs for detection, diagnosis and imaging, indexed by particle type.

\begin{tabular}{|c|c|c|}
\hline Type of particle & Target & References \\
\hline \multirow[t]{11}{*}{ Gold NPs } & Escherichia coli & Richards et al. (2014), Qi et al. (2018), Ajish et al. (2020) \\
\hline & Pseudomonas aeruginosa & Qi et al. (2018), Khan et al. (2019), Zhang et al. (2020) \\
\hline & $\begin{array}{l}\text { Micrococcus luteus, Vibrio alginolyticus, Shewanella alginolyticus, } \\
\text { Desulfovibrio desulfuricans }\end{array}$ & Qi et al. (2018) \\
\hline & Human influenza virus & $\begin{array}{l}\text { Marín et al. (2013), Poonthiyil et al. (2015b), Zhang et al. (2016), } \\
\text { Zheng et al. (2017) }\end{array}$ \\
\hline & Sambucus nigra agglutinin (SNA) & Zhang et al. (2016) \\
\hline & SARS-CoV-2 spike protein (VLPs) & Baker et al. (2020) \\
\hline & DC-SIGN/R proteins & Budhadev et al. (2020) \\
\hline & Escherichia coli enterotoxin LTB & Poonthiyil et al. (2015a) \\
\hline & SIGLEC proteins & Schofield et al. (2016) \\
\hline & Galectin-1 & García Calavia et al. (2018) \\
\hline & Lung cancer cells & Adokoh et al. (2020) \\
\hline \multirow[t]{2}{*}{ Silver NPs } & Escherichia coli & Wang et al. (2017) \\
\hline & Cholera toxin B subunit (CTB) & Simpson et al. (2016) \\
\hline \multirow{4}{*}{$\begin{array}{l}\text { Magnetic NPs (ferrite, } \\
\text { alumina) }\end{array}$} & Escherichia coli & Park et al. (2017), Raval et al. (2017) \\
\hline & Helicobacter pylori & Park et al. (2015) \\
\hline & Mycobacterium smegmatis & Jayawardana et al. (2015) \\
\hline & Shiga-like toxin 1 (Stx1) & Kuo et al. (2015) \\
\hline \multirow[t]{3}{*}{ Silicon QDs } & Escherichia coli & Jayawardena et al. (2013) \\
\hline & Mycobacterium smegmatis & Jayawardana et al. (2015) \\
\hline & Cancer cells & Ahire et al. (2015), Lai et al. (2016), Hsu et al. (2017), Li et al. (2020) \\
\hline \multirow[t]{2}{*}{ Cadmium QDs } & DC-SIGN/R proteins & Guo et al. (2016), Guo et al. (2017) \\
\hline & Plant lectins (ConA, PNA) & Ma et al. (2014) \\
\hline \multirow[t]{2}{*}{ QDs + gold NPs } & Cholera toxin B subunit (CTB) & Ahn et al. (2016) \\
\hline & Concanavalin A (ConA) & Zhang et al. (2018) \\
\hline
\end{tabular}

Nanoparticles have a high surface to volume ratio, enabling multivalent ligand presentation, which has been widely exploited to overcome the inherently weak nature of carbohydrate-protein interactions (Lundquist and Toone, 2002). However, a too high density of the carbohydrate on the surface can hamper accessibility of the glycan to protein partners-a challenge that can be addressed through longer, more flexible tethers (Marradi et al., 2013; Compostella et al., 2017).

More recent efforts has seen the exploration of semiconductor nanoparticles (quantum dots-QDs) in the field of diagnostics (Medintz et al., 2005; Michalet et al., 2005). In the range of $1-10 \mathrm{~nm}$, cadmium-based QDs are inherently fluorescent (Alivisatos, 1996; Bruchez et al., 1998; Li et al., 2015). The evident cytotoxicity of semi-conductor QDs prompted the exploration of the more biocompatible silicon quantum dots (SiQDs) (Robidillo and Veinot, 2020), which had no effect on cell viability in Shewanella oneidensis and Bacillus subtilis (Pramanik et al., 2018). A recent comprehensive review of QDs, glyco-QDs and their synthesis and applications in biosensing is suggested (Marradi et al., 2021).

To date, glyconanoparticle-based detection assays have proven effective for lectin detection, including those associated with viruses and bacteria. The tuneable optical properties of gold NPs (AuNPs) and silver nanoparticles (AgNPs) make them ideal candidates for use in simple colorimetric assays (Schofield et al., 2006; Marín et al., 2015). Given the pervasive nature of carbohydrates in biology (Dedola et al., 2020), and aberrant expression of carbohydrates and carbohydrate-binding receptors on the surface of some cancer cells, glyconanoparticles have also been extensively studied to target, image and treat tumours (Hockl et al., 2016; Torres-Pérez et al., 2020). Herein, we survey recent advances in these fields: key features of the systems discussed can be found in Figure $\mathbf{1}$ and Table $\mathbf{1}$.

\section{LECTINS/PROTEIN TOXINS}

The plant lectin Concanavalin A (ConA) has been widely used as a model to develop carbohydrate-based lectin detection systems. The specific interaction between glucosamine-functionalised AuNPs and ConA has been reported (Di Silvio et al., 2018) to study the intracellular exchange of protein corona, confirming that specific interactions between lectins and NPs surface ligands contribute to retain the lectins on the surface of the NP. Thiolated mannosides have been used to functionalise AuNPs, as well as $\mathrm{ZnS} / \mathrm{CdSe}$ QDs, for the detection of ConA (Zhang et al., 2018). In this, and several other studies, fluorescence quenching via Förster resonance energy transfer (FRET) was used as a switch on-off effect during the assay.

$\mathrm{CdSe} / \mathrm{ZnS}$ QDs have been functionalised with quinolyl glucose (Glc) or quinolyl galactose (Gal) for the detection of ConA and peanut agglutinin (PNA), respectively (Ma et al., 2014). Both Glc and Gal systems exploited the FRET effect between the QDs and the quinone, with the fluorescence recovery achieved in the presence of the specific lectins. Other studies applied glycoQDs for the detection of lectins with a dual-colour system based on glucose-QDs for the detection of ConA and galactose-QDs for the detection of PNA, allowing the discrimination between both lectins in the same sample 
(Zhang et al., 2013). More recent work combined different glycoQDs with red, green and yellow emissions for selective detection between ConA, PNA, Pisum sativum agglutinin, wheat germ agglutinin and Ricinus communis agglutinin 120 (Wang et al., 2018).

The detection of bacterial toxins has attracted attention in diagnostic. The detection of Cholera toxin (CTB) (Schofield et al., 2007) and the detection of heat-labile enterotoxin B subunit (LTB) from E. coli (Poonthiyil et al., 2015a), both based on galactose-functionalised AuNPs, have been reported. In the latter, $12 \mathrm{~nm}$ diameter AuNPs produced the most significant shift in absorbance and the toxin was detected at a concentration of $100 \mathrm{nM}$. The detection of Shiga-like toxin 1 (Stx1), often associated with bacteria such as E. coli or Shigella dysenteriae, has been also achieved with glyconanoparticles. A systematic comparison of tether lengths and nanoparticle sizes was made using globotriose-functionalised AuNPs (Chien et al., 2008), showing that larger particles with longer tethers allowed a more efficient binding to Stx 1 when they were compared to the free globotriose ligand. A different approach was adopted using a magnetic nanoparticle-based system (MNPs) (Kuo et al., 2015). Here, the glycan functionality was conveniently obtained by functionalising $30 \mathrm{~nm}$ particles with pigeon ovalbumin, a glycoprotein containing an oligosaccharide ligand for Stx1, namely Gal- $\alpha(1 \rightarrow 4)$-Gal- $\beta(1 \rightarrow 4)$-GlcNAc. The assay showed specificity for Stx1 in complex matrices, where the glyconanoparticles and associated protein toxin were isolated by magnetic extraction and analysed by MALDI-ToF to confirm the presence of St $\times 1$.

Chromophores are often combined with either an enhancing or a supressing counterpart. A surface-enhanced Raman spectroscopy (SERS)-based assay for the detection of CTB was developed using silver nanoparticles presenting both PEGylated galactose and sialic acid (SA) (Simpson et al., 2016) (optimised 15:1 ratio). This assay allowed the low $\mathrm{nM}$ detection of the toxin in simulated freshwater samples.

A system comprising galactose-AuNPs and amine-QDs for the detection of CTB has been developed (Ahn et al., 2016). The assay was based on the inhibition of fluorescence via FRET, upon binding of the QDs to the AuNPs via hydrogen bonds formation between the amines on the QD and the hydroxyl groups of galactose-AuNPs. In the presence of CTB, the hydrogen bonds are disrupted liberating the amine-QDs and activating their fluorescence.

Selectins have attracted attention as biomarkers for the diagnosis of brain inflammation. Lewis $\mathrm{X}\left(\mathrm{Le}^{\mathrm{x}}\right)$-capped ferrite nanoparticles were designed for the selective in vivo targeting of such receptors (Van Kasteren et al., 2009). This work showed potential for the early diagnosis of neuropathologies such us dementia, encephalitis or Parkinson's disease.

\section{VIRUSES}

Influenza virus remains a serious global health concern, causing ca. 300,000 deaths every year (Paget et al., 2019). The affinity between hemagglutinin on the surface of the virus and sialic acid, which forms the basis of host cell adhesion and invasion during infection, has been explored for the development of rapid diagnostics. Human influenza strains preferentially bind to a2,6-sialylgalactose, while the animal viruses prefer the a2,3linked isomer (Marín et al., 2013). A collection of AuNPs functionalised with seven different sialic acid derivatives (Zheng et al., 2017) was used to successfully detect 14 different influenza strains enabling discrimination from other respiratory viruses, such as hRSV and avian influenza virus.

A bi-antennary sialoglycopeptide extracted from egg yolk has been used to functionalise AuNPs for the colorimetric detection of human influenza virus (Poonthiyil et al., 2015b) achieving a detection limit of $71 \mathrm{nM}$ and the effective detection of two H1N1 strains, A/PuertoRico/8/34 and A/New Caledonia/29/1999.

A straightforward methodology for the preparation of AuNPs coated with a2,6-sialyllactose-containing polymer has been reported by Zhang et al. (Zhang et al., 2016) and tested for aggregation with Sambucus nigra agglutinin and influenza virus using dynamic light scattering or transmission electron microscopy (TEM).

Since the pandemic crisis caused by COVID-19 in early 2020, efforts have been made to detect SARS-CoV2 using glyconanoparticles. A lateral flow system for the rapid detection of coronavirus spike proteins was recently reported (Baker et al., 2020). Sialic acid-linked poly-(2-hydroxyethyl acrylate) (PHEA) was used to functionalise AuNPs, and binding to the target spike proteins was evaluated by biolayer interferometry. The system was transferred into lateral flow format enabling the rapid, sensitive and selective detection of virus-like particles presenting the SARS-CoV2 spike protein.

Virus-glycan interactions have been shown to prevent virus internalisation in human cells through DC-SIGN/R receptors, which function as an entrance gate for viruses such as HIV or Ebola. AuNPs functionalised with the same high-mannose glycans present in the HIV glycoprotein gp120 (Chiodo et al., 2013) together with PEGylated $\alpha$-fucosylamides (Arosio et al., 2014), both successfully interacted with the DC-SIGN receptor with a comparable efficiency. Other works have demonstrated that such virus uptake channels can be blocked by multivalent glyconanoparticles, and their efficacy can be modulated by varying the sugar density on the nanoparticle surface (Guo et al., 2016). In addition, the glyconanoparticle approach can be used to quantify binding affinity for DC-SIGN/R receptors as well as to inhibit viral cell entry (Guo et al., 2017). Extension of this work explored the interaction of mannose (Man)functionalised AuNPs and DC-SIGN (Budhadev et al., 2020).

\section{BACTERIA}

The detection of bacterial pathogens represents an ongoing need in the field of health care. To target the E. coli fimbrial adhesion FimH, mannose-coated CdS QDs have been used (Mukhopadhyay et al., 2009). More recent work screened AuNPs functionalised with either mannose or glucose (Richards et al., 2014) to detect E. coli K-12 strain (FimH+) and using the TOP10 strain (FimH-) as negative control. The 
stability of the nanoparticles in solution was improved by using a PEG-3000 tether, rather than directly binding the respective thiosugar to the AuNPs.

Recently, a detection system for $E$. coli based on the fluorescent properties of glycoacrylamides (Glc-bis) has been reported (Ajish et al., 2020), where self-aggregation-induced $\pi$ interactions between the acrylamide moiety installed on the glucose generate the fluorescence of the polymer (Ajish et al., 2018). The fluorescence of the glycopolymer is quenched by the AuNPs, but in the presence of a glucose-binding target the Glc-bis ligand is removed from the surface of the AuNPs, reactivating its fluorescence. This turn on-based fluorescent system afforded a simple means to detect $E$. coli.

Focusing on the same FimH target, mannose-stabilised AgNPs have been synthesised for the selective detection of $E$. coli strain O157:H7 (Wang et al., 2017). Specificity was tested against a series of bacterial strains, demonstrating that the mannosestabilised AgNPs were specific for the O157:H7 E. coli strain. The AgNPs construct exhibited a dual activity resulting from the targeting role of the glycan and the bactericidal properties of silver, leading to the rapid sterilisation of an E. coli-contaminated sample.

Given the associated cell surface lectins (LecA, B), galactoseor fucose-functionalised AuNPs have been used to target, detect and kill Pseudomonas aeruginosa (Zhang et al., 2020). The functionalisation was performed via copper-free click chemistry between azidobutyl glycosides and a cyclooctynebased thioctic acid linker (Karamanska et al., 2005). Successively, the nanoparticles were decorated with the antibiotic ceftazidime via non-covalent interaction. The antibiotic activity was studied through photo-and chemotherapy, revealing that the system was selective for $P$. aeruginosa in the presence of E. coli or methicillin-resistant Staphylococcus aureus.

Gold-coated, Mn-doped magnetite nanoparticles functionalised with mannosamine have been used to target E.coli (Park et al., 2017), as judged by TEM. Using a more sophisticated system, Raval et al. targeted E. coli with the bacteria-specific glycoconjugate GM3 [Neu5Ac(a2-3)-Gal$\beta(1-4)$ Glc- $\beta$ sp] "clicked" onto the surface of magnetite nanoparticles. Anti-bacterial effects were achieved via magnetically-mediated energy delivery (MagMED), where heat is generated in situ by the application of alternating magnetic fields (Raval et al., 2017).

The modulation of binding and uptake of several types of NPs by E. coli using different glycans has been reported (Jayawardena et al., 2013). The carbohydrate moiety selected to stabilise the NPs (SiNPs, MNPs, Si-coated MNPs and Si-coated CdQDs) directed the specificity of the binding. Using maltoheptaose for the functionalisation of the particles remarkably improved their internalisation by the bacteria, whereas using mannose favoured the surface binding, due to the interaction of the NPs with FimH adhesins.

AuNPs functionalised with sulfated seaweed polysaccharide fucoidan showed inhibitory effects on $P$. aeruginosa growth and biofilm formation, decreasing the virulence and motility of the bacteria (Khan et al., 2019).
Fluorescent $\mathrm{Cu} / \mathrm{CdSQDs}$ functionalised with glucose, stachyose or raffinose showed discrimination between different bacteria demonstrated via linear discrimination analysis of the fluorescence signals (Qi et al., 2018). The assay could be performed in $30 \mathrm{~min}$ and was able to selectively differentiate between E. coli, P. aeruginosa, Micrococcus luteus, Vibrio alginolyticus, Shewanella algae and Desulfovibrio desulfuricans.

A fluorescent magnetic assay to target, block or extract Helicobacter pylori based on fucose-containing oligosaccharides $\mathrm{Le}^{\mathrm{a}}$, $\mathrm{Le}^{\mathrm{b}}$ or blood group $\mathrm{H}$ type 1 coupled to cobalt-ferrite magnetic nanoshells has been reported (Park et al., 2015). Binding of the nanoparticles to $H$. pylori was confirmed by confocal microscopy, while incubation of the bacteria with mammalian cells in presence of these fucose-NPs prevented the adhesion of $H$. pylori to the cells.

Tuberculosis remains an important disease globally and early diagnosis represents an unmet need. A detection assay for Mycobacterium smegmatis has been developed (Jayawardana et al., 2015) based on silica and iron NPs. The authors assembled a small library of trehalose-stabilised NPs, using previously reported methodology (Wang et al., 2013), and demonstrated the ability of the glyconanoparticles to selectively bind M. smegmatis over mammalian cells.

\section{CANCER}

The imaging of tumours and the early detection of cancer biomarkers is topical. One of the first reported application of glyco-QDs was dedicated to the study of asialoglycoprotein receptor interaction with galactose-terminated QDs in liver cancer cell line HepG2 (Kikkeri et al., 2009). Using flow cytometry, the authors demonstrated the increased uptake of galactosamine-capped QDs in comparison to sugar-free or galactose-capped-QDs.

Sialic acid-binding immunoglobulin-type lectins (SIGLECs), together with galactose-binding galectins, are cancer markers of increasing interest (Cagnoni et al., 2016). Galectin-1, 7, and 9 have been found to be overexpressed in cancer cells and therefore represent highly relevant targets in cancer diagnostics (Sun et al., 2019). A plasmonic system based on sialic acid functionalised AuNPs has been designed for the detection of SIGLECs (Schofield et al., 2016). The assay provided a colour change upon aggregation of the AuNPs in the presence of SIGLECs (in solution), or could be localised by TEM when expressed on Chinese hamster ovary cell-surface. Recently, AuNPs stabilised with acetylated mannose were used in an image-based assay to detect A549 lung cancer cells (Adokoh et al., 2020). A comparison between different mannose-functionalised NPs, revealed that those containing acetylated mannose had better selectivity towards A549 lung cancer cells than to healthy peripheral blood mononuclear cells.

García Calavia et al. reported an anti-cancer photodynamic therapy system based on bi-functionalised AuNPs (García Calavia et al., 2018). The galatose-terminal lactose disaccharide was used to selectively target galectin-1, which is overexpressed in certain breast cancer cells such as MDA-MB-231 or SK-BR-3, and 
a derivative of phthalocyanine was used as photosensitiser. The bi-functionalised glyco-nanoparticle conjugates could be used to achieve selective breast cancer cell death upon irradiation of the photosensitiser at $633 \mathrm{~nm}$, resulting harmless to MCF-10A cells.

Human carcinoma cells have been targeted with silicon-based glyco-quantum dots (Ahire et al., 2015). Work has been done to prove that in some applications, carbohydrate-functionalised SiQDs (using galactose, mannose, glucose or lactose) are nontoxic whereas the unfunctionalised SiQDs are. Lai et al. reported an imaging system for B16F10 melanoma cells, based on low affinity carbohydrate-carbohydrate interactions between ganglioside GM3, present on the surface of cancer cells, and Gg3-functionalised $4 \mathrm{~nm}$ SiQDs (Lai et al., 2016). Confocal fluorescence microscopy was used to confirm that the small Gg3-SiQDs could be used to image cancer cells. A similar approach showed the uptake of glucose-functionalised $4 \mathrm{~nm}$ SiQDs by HeLa cells (Hsu et al., 2017), while a study of the particle size-dependent uptake of mannose-functionalised SiQDs by MDA-MB-231 breast cancer cells has been reported recently (Li et al., 2020), showing that the larger $400 \mathrm{~nm}$ Man-SiQDs have the highest uptake rate by cells.

Magnetic glyconanoparticles have been employed in combination with magnetic resonance imaging (MRI) to detect cancer cells, avoiding the need of labelling the cells beforehand (Ei-Boubbou et al., 2010). A collection of ferrite glyconanoparticles functionalised with either mannose, fucose, galactose, sialic acid or $\mathrm{N}$-acetylglucosamine were screened against a wide variety of cancer cell lines to determine the binding preferences. In other work, AuNPs bi-functionalised with thiolated glycans (glucose, galactose or mannose) and gadolinium chelates-as paramagnetic labels for MR-were used to target hepatocytes, murine glioma cells and lymphoma cell lines (Irure et al., 2013).

\section{REFERENCES}

Adokoh, C. K., Keter, F. K., Kinfe, H. H., Tshikhudo, R., and Darkwa, J. (2020). Development and Characterization of Functionalized Glyco Thiolate Capped Gold Nanoparticles for Biological Applications. RSC Med. Chem. 11 (2), 283-292. doi:10.1039/c9md00493a

Ahire, J. H., Behray, M., Webster, C. A., Wang, Q., Sherwood, V., Saengkrit, N., et al. (2015). Synthesis of Carbohydrate Capped Silicon Nanoparticles and Their Reduced Cytotoxicity, In Vivo Toxicity, and Cellular Uptake. Adv. Healthc. Mater. 4 (12), 1877-1886. doi:10.1002/adhm.201500298

Ahn, K.-S., Lim, K. R., Jeong, D., Lee, B. Y., Kim, K. S., and Lee, W.-Y. (2016). Fluorescence Energy Transfer Inhibition Bioassay for Cholera Toxin Based on Galactose-Stabilized Gold Nanoparticles and Amine-Terminated Quantum Dots. Microchemical J. 124, 9-14. doi:10.1016/ j.microc.2015.07.007

Ajish, J. K., Ajish Kumar, K. S., Ruhela, A., Subramanian, M., Ballal, A. D., and Kumar, M. (2018). AIE Based Fluorescent Self Assembled Glycoacrylamides for E.Coli Detection and Cell Imaging. Sensors Actuators B: Chem. 255, 1726-1734. doi:10.1016/j.snb.2017.08.188

Ajish, J. K., Kanagare, A. B., Kumar, K. S. A., Subramanian, M., Ballal, A. D., and Kumar, M. (2020). Self-Assembled Glycobis(acrylamide)-Stabilized Gold Nanoparticles for Fluorescent Turn-On Sensing of Lectin and Escherichia coli. ACS Appl. Nano Mater. 3 (2), 1307-1317. doi:10.1021/acsanm.9b02127

Alivisatos, A. P. (1996). Semiconductor Clusters, Nanocrystals, and Quantum Dots. Science 271 (5251), 933-937. doi:10.1126/science.271.5251.933
A reversal approach in the functionalisation of AuNPs has been used by immobilising lectin on QDs for the detection of glycan for in vitro and in vivo imaging of tumours, together with detection and theranostic applications (Ashree et al., 2020).

\section{CONCLUSION}

The range of applications of glyconanoparticles and the related carbohydrate-functionalised quantum dots is everexpanding, with applications across detection for diagnosis of infectious diseases and cancer. For in vivo theranostic applications (i.e., combined diagnosis and therapy), efforts to produce more robust and less toxic nanomaterials is key to future in vivo applications. The field continues to progress at pace and impactful developments in the coming decade are anticipated.

\section{AUTHOR CONTRIBUTIONS}

All authors listed have made a substantial, direct, and intellectual contribution to the work and approved it for publication.

\section{FUNDING}

This work was supported by the Marie Skłodowska-Curie Actions (MSCA), as part of the Horizon 2020 programme funded by the EU Commission (Grant Agreement 814102-Sweet Crosstalk). The authors acknowledge the University of East Anglia and the Quadram Institute, Norwich as hosts for this project.

Arosio, D., Chiodo, F., Reina, J. J., Marelli, M., Penadés, S., Van Kooyk, Y., et al. (2014). Effective Targeting of DC-SIGN by $\alpha$-Fucosylamide Functionalized Gold Nanoparticles. Bioconjug. Chem. 25 (12), 2244-2251. doi:10.1021/ bc500467u

Ashree, J., Wang, Q., and Chao, Y. (2020). Glyco-functionalised Quantum Dots and Their Progress in Cancer Diagnosis and Treatment. Front. Chem. Sci. Eng. 14 (3), 365-377. doi:10.1007/s11705-019-1863-7

Baker, A. N., Richards, S.-J., Guy, C. S., Congdon, T. R., Hasan, M., Zwetsloot, A. J., et al. (2020). The SARS-COV-2 Spike Protein Binds Sialic Acids and Enables Rapid Detection in a Lateral Flow Point of Care Diagnostic Device. ACS Cent. Sci. 6, 2046-2052. doi:10.1021/acscentsci.0c00855

Bruchez, M., Moronne, M., Gin, P., Weiss, S., and Alivisatos, A. P. (1998). Semiconductor Nanocrystals as Fluorescent Biological Labels. Science 281 (5385), 2013-2016. doi:10.1126/science.281.5385.2013

Budhadev, D., Poole, E., Nehlmeier, I., Liu, Y., Hooper, J., Kalverda, E., et al. (2020). Glycan-Gold Nanoparticles as Multifunctional Probes for Multivalent LectinCarbohydrate Binding: Implications for Blocking Virus Infection and Nanoparticle Assembly. J. Am. Chem. Soc. 142, 18022-18034. doi:10.1021/jacs.0c06793

Cagnoni, A. J., Pérez Sáez, J. M., Rabinovich, G. A., and Mariño, K. V. (2016). Turning-off Signaling by Siglecs, Selectins, and Galectins: Chemical Inhibition of Glycan-dependent Interactions in Cancer. Front. Oncol. 6, 1-21. doi:10.3389/ fonc.2016.00109

Chaudhary, P. M., Sangabathuni, S., Murthy, R. V., Paul, A., Thulasiram, H. V., and Kikkeri, R. (2015). Assessing the Effect of Different Shapes of Glyco-Gold Nanoparticles on Bacterial Adhesion and Infections. Chem. Commun. 51 (86), 15669-15672. doi:10.1039/c5cc05238f 
Chen, X., Ramström, O., and Yan, M. (2014). Glyconanomaterials: Emerging Applications in Biomedical Research. Nano Res. 7, 1381-1403. doi:10.1007/ s12274-014-0507-y

Chien, Y.-Y., Jan, M.-D., Adak, A. K., Tzeng, H.-C., Lin, Y.-P., Chen, Y.-J., et al. (2008). Globotriose-functionalized Gold Nanoparticles as Multivalent Probes for Shiga-like Toxin. ChemBioChem 9 (7), 1100-1109. doi:10.1002/cbic.200700590

Chiodo, F., Marradi, M., Tefsen, B., Snippe, H., van Die, I., and Penadés, S. (2013). High Sensitive Detection of Carbohydrate Binding Proteins in an ELISA-Solid Phase Assay Based on Multivalent Glyconanoparticles. PLoS ONE 8 (8), e73027-11. doi:10.1371/journal.pone.0073027

Compostella, F., Pitirollo, O., Silvestri, A., and Polito, L. (2017). Glyco-gold Nanoparticles: Synthesis and Applications. Beilstein J. Org. Chem. 13, 1008-1021. doi:10.3762/bjoc.13.100

de la Fuente, J. M., Barrientos, A. G., Rojas, T. C., Rojo, J., Cañada, J., Fernández, A., et al. (2001). Gold Glyconanoparticles as Water-Soluble Polyvalent Models to Study Carbohydrate Interactions. Angew. Chem. Int. Edition English 40 (12), 2257-2261. doi:10.1002/1521-3773(20010618)40:12<2257::AID-ANIE2257>3.0.CO;2-S

de la Fuente, J. M., and Penadés, S. (2006). Glyconanoparticles: Types, Synthesis and Applications in Glycoscience, Biomedicine and Material Science. Biochim. Biophys. Acta (Bba) - Gen. Subjects 1760 (4), 636-651. doi:10.1016/ j.bbagen.2005.12.001

Dedola, S., Rugen, M. D., Young, R. J., and Field, R. A. (2020). Revisiting the Language of Glycoscience: Readers, Writers and Erasers in Carbohydrate Biochemistry. ChemBioChem 21 (3), 423-427. doi:10.1002/cbic.201900377

Di Silvio, D., Silvestri, A., Lay, L., Polito, L., and Moya, S. E. (2018). Impact of ConcanavalinA Affinity in the Intracellular Fate of Protein Corona on Glucosamine Au Nanoparticles. Sci. Rep. 8 (1), 1-11. doi:10.1038/s41598018-27418-w

Dosekova, E., Filip, J., Bertok, T., Both, P., Kasak, P., and Tkac, J. (2017). Nanotechnology in Glycomics: Applications in Diagnostics, Therapy, Imaging, and Separation Processes. Med. Res. Rev. 37 (3), 514-626. doi:10.1002/med.21420

El-Boubbou, K., Zhu, D. C., Vasileiou, C., Borhan, B., Prosperi, D., Li, W., et al. (2010). Magnetic Glyco-Nanoparticles: A Tool to Detect, Differentiate, and Unlock the Glyco-Codes of Cancer via Magnetic Resonance Imaging. J. Am. Chem. Soc. 132 (12), 4490-4499. doi:10.1021/ja100455c

Fratila, R. M., Moros, M., and de la Fuente, J. M. (2016). Recent Advances in Biosensing Using Magnetic Glyconanoparticles. Anal. Bioanal. Chem. 408 (7), 1783-1803. doi:10.1007/s00216-015-8953-2

García Calavia, P., Chambrier, I., Cook, M. J., Haines, A. H., Field, R. A., and Russell, D. A. (2018). Targeted Photodynamic Therapy of Breast Cancer Cells Using Lactose-Phthalocyanine Functionalized Gold Nanoparticles. J. Colloid Interf. Sci. 512, 249-259. doi:10.1016/j.jcis.2017.10.030

Guo, Y., Nehlmeier, I., Poole, E., Sakonsinsiri, C., Hondow, N., Brown, A., et al. (2017). Dissecting Multivalent Lectin-Carbohydrate Recognition Using Polyvalent Multifunctional Glycan-Quantum Dots. J. Am. Chem. Soc. 139 (34), 11833-11844. doi:10.1021/jacs.7b05104

Guo, Y., Sakonsinsiri, C., Nehlmeier, I., Fascione, M. A., Zhang, H., Wang, W., et al. (2016). Compact, Polyvalent Mannose Quantum Dots as Sensitive, Ratiometric FRET Probes for Multivalent Protein-Ligand Interactions. Angew. Chem. Int. Ed. 55 (15), 4738-4742. doi:10.1002/anie.201600593

Hockl, P. F., Wolosiuk, A., Pérez-Sáez, J. M., Bordoni, A. V., Croci, D. O., ToumTerrones, Y., et al. (2016). Glyco-nano-oncology: Novel Therapeutic Opportunities by Combining Small and Sweet. Pharmacol. Res. 109, 45-54. doi:10.1016/j.phrs.2016.02.005

Hsu, C.-W., Septiadi, D., Lai, C.-H., Chen, P., Seeberger, P. H., and De Cola, L. (2017). Glucose-Modified Silicon Nanoparticles for Cellular Imaging. ChemPlusChem 82 (4), 660-667. doi:10.1002/cplu.201700054

Irure, A., Marradi, M., Arnáiz, B., Genicio, N., Padro, D., and Penadés, S. (2013). Sugar/ gadolinium-loaded Gold Nanoparticles for Labelling and Imaging Cells by Magnetic Resonance Imaging. Biomater. Sci. 1 (6), 658-668. doi:10.1039/c3bm60032g

Jayawardana, K. W., Jayawardena, H. S. N., Wijesundera, S. A., De Zoysa, T., Sundhoro, M., and Yan, M. (2015). Selective Targeting of Mycobacterium Smegmatis with Trehalose-Functionalized Nanoparticles. Chem. Commun. 51 (60), 12028-12031. doi:10.1039/c5cc04251h

Jayawardena, H. S. N., Jayawardana, K. W., Chen, X., and Yan, M. (2013). Maltoheptaose Promotes Nanoparticle Internalization by Escherichia coli. Chem. Commun. 49 (29), 3034-3036. doi:10.1039/c3cc40491a
Karamanska, R., Mukhopadhyay, B., Russell, D. A., and Field, R. A. (2005). Thioctic Acid Amides: Convenient Tethers for Achieving Low Nonspecific Protein Binding to Carbohydrates Presented on Gold Surfaces. Chem. Commun. 120 (26), 3334-3336. doi:10.1039/b503843j

Khan, F., Manivasagan, P., Lee, J.-W., Pham, D., Oh, J., and Kim, Y.-M. (2019). Fucoidan-stabilized Gold Nanoparticle-Mediated Biofilm Inhibition, Attenuation of Virulence and Motility Properties in pseudomonas Aeruginosa Pao1. Mar. Drugs 17 (4), 208-219. doi:10.3390/md17040208

Kikkeri, R., Lepenies, B., Adibekian, A., Laurino, P., and Seeberger, P. H. (2009). In Vitro imaging and In Vivo Liver Targeting with Carbohydrate Capped Quantum Dots. J. Am. Chem. Soc. 131 (6), 2110-2112. doi:10.1021/ja807711w

Kuo, F.-Y., Chang, B.-Y., Wu, C.-Y., Mong, K.-K. T., and Chen, Y.-C. (2015). Magnetic Nanoparticle-Based Platform for Characterization of Shiga-like Toxin 1 from Complex Samples. Anal. Chem. 87 (20), 10513-10520. doi:10.1021/acs.analchem.5b02712

Kveton, F., Blsakova, A., Kasak, P., and Tkac, J. (2020). Glycan Nanobiosensors. Nanomaterials 10 (7), 1406-1430. doi:10.3390/nano10071406

Lai, C.-H., Hütter, J., Hsu, C.-W., Tanaka, H., Varela-Aramburu, S., De Cola, L., et al. (2016). Analysis of Carbohydrate-Carbohydrate Interactions Using SugarFunctionalized Silicon Nanoparticles for Cell Imaging. Nano Lett. 16 (1), 807-811. doi:10.1021/acs.nanolett.5b04984

Li, H.-Y., Lin, H.-C., Huang, B.-J., Kai Lo, A. Z., Saidin, S., and Lai, C.-H. (2020). Size Preferences Uptake of Glycosilica Nanoparticles to MDA-MB-231 Cell. Langmuir 36 (38), 11374-11382. doi:10.1021/acs.langmuir.0c02297

Li, Y., Shi, F., Cai, N., and Su, X. (2015). A Biosensing Platform for Sensitive Detection of Concanavalin A Based on Fluorescence Resonance Energy Transfer from CdTe Quantum Dots to Graphene Oxide. New J. Chem. 39 (8), 6092-6098. doi:10.1039/c5nj00942a

Lundquist, J. J., and Toone, E. J. (2002). The Cluster Glycoside Effect. Chem. Rev. 102 (2), 555-578. doi:10.1021/cr000418f

Ma, W., Liu, H.-T., He, X.-P., Zang, Y., Li, J., Chen, G.-R., et al. (2014). Target-specific Imaging of Transmembrane Receptors Using Quinonyl Glycosides Functionalized Quantum Dots. Anal. Chem. 86 (11), 5502-5507. doi:10.1021/ac501463u

Marín, M. J., Rashid, A., Rejzek, M., Fairhurst, S. A., Wharton, S. A., Martin, S. R., et al. (2013). Glyconanoparticles for the Plasmonic Detection and Discrimination between Human and Avian Influenza Virus. Org. Biomol. Chem. 11 (41), 7101-7107. doi:10.1039/c3ob41703d

Marín, M. J., Schofield, C. L., Field, R. A., and Russell, D. A. (2015). Glyconanoparticles for Colorimetric Bioassays. Analyst 140 (1), 59-70. doi:10.1039/c4an01466a

Marradi, M., Chiodo, F., García, I., and Penadés, S. (2013). Glyconanoparticles as Multifunctional and Multimodal Carbohydrate Systems. Chem. Soc. Rev. 42 (11), 4728-4745. doi:10.1039/c2cs35420a

Marradi, M., Tricomi, J., Matassini, C., and Richichi, B. (2021). "Carbohydrate Functionalized Quantum Dots in Sensing, Imaging and Therapy Applications," in Comprehensive Glycoscience. Editor J. Barchi. 2nd ed. (Amsterdam: Elsevier), 433-472. doi:10.1016/b978-0-12-819475-1.00041-9

Medintz, I. L., Uyeda, H. T., Goldman, E. R., and Mattoussi, H. (2005). Quantum Dot Bioconjugates for Imaging, Labelling and Sensing. Nat. Mater 4 (6), 435-446. doi:10.1038/nmat1390

Michalet, X., Pinaud, F. F., Bentolila, L. A., Tsay, J. M., Doose, S., Li, J. J., et al. (2005). Quantum Dots for Live Cells, In Vivo Imaging, and Diagnostics. Science 307 (5709), 538-544. doi:10.1126/science.1104274

Mukhopadhyay, B., Martins, M. B., Karamanska, R., Russell, D. A., and Field, R. A. (2009). Bacterial Detection Using Carbohydrate-Functionalised CdS Quantum Dots: a Model Study Exploiting E. coli Recognition of Mannosides. Tetrahedron Lett. 50 (8), 886-889. doi:10.1016/j.tetlet.2008.12.029

Paget, J., Spreeuwenberg, P., Charu, V., Taylor, R. J., Iuliano, A. D., Bresee, J., et al. (2019). Global Mortality Associated with Seasonal Influenza Epidemics: New burden Estimates and Predictors from the GLaMOR Project. J. Glob. Health 9 (2), 1-12. doi:10.7189/jogh.09.020421

Park, J. C., Lee, G. T., and Seo, J. H. (2017). Mannose-functionalized Core@shell Nanoparticles and Their Interactions with Bacteria. J. Mater. Sci. 52 (3), 1534-1545. doi:10.1007/s10853-016-0448-9

Park, S., Kim, G.-H., Park, S.-H., Pai, J., Rathwell, D., Park, J.-Y., et al. (2015). Probing Cell-Surface Carbohydrate Binding Proteins with Dual-Modal GlycanConjugated Nanoparticles. J. Am. Chem. Soc. 137 (18), 5961-5968. doi:10.1021/ jacs.5b00592 
Poonthiyil, V., Golovko, V. B., and Fairbanks, A. J. (2015a). Size-optimized Galactose-Capped Gold Nanoparticles for the Colorimetric Detection of Heat-Labile Enterotoxin at Nanomolar Concentrations. Org. Biomol. Chem. 13 (18), 5215-5223. doi:10.1039/c5ob00447k

Poonthiyil, V., Nagesh, P. T., Husain, M., Golovko, V. B., and Fairbanks, A. J. (2015b). Gold Nanoparticles Decorated with Sialic Acid Terminated Biantennary N-Glycans for the Detection of Influenza Virus at Nanomolar Concentrations. ChemistryOpen 4 (6), 708-716. doi:10.1002/open.201500109

Pramanik, S., Hill, S. K. E., Zhi, B., Hudson-Smith, N. V., Wu, J. J., White, J. N., et al. (2018). Comparative Toxicity Assessment of Novel Si Quantum Dots and Their Traditional Cd-Based Counterparts Using Bacteria Models Shewanella Oneidensis and Bacillus Subtilis. Environ. Sci. Nano 5 (8), 1890-1901. doi:10.1039/c8en00332g

Qi, P., Chen, X., Sun, Y., and Zhang, D. (2018). Multivalent Glycosylated Cu:CdS Quantum Dots as a Platform for Rapid Bacterial Discrimination and Detection. Sensors Actuators B: Chem. 254, 431-436. doi:10.1016/j.snb.2017.07.130

Raval, Y. S., Fellows, B. D., Murbach, J., Cordeau, Y., Mefford, O. T., and Tzeng, T. R. J. (2017). Multianchored Glycoconjugate-Functionalized Magnetic Nanoparticles: A Tool for Selective Killing of Targeted Bacteria via Alternating Magnetic Fields. Adv. Funct. Mater. 27 (26), 1701473. doi:10.1002/adfm.201701473

Richards, S.-J., Fullam, E., Besra, G. S., and Gibson, M. I. (2014). Discrimination between Bacterial Phenotypes Using Glyco-Nanoparticles and the Impact of Polymer Coating on Detection Readouts. J. Mater. Chem. B 2 (11), 1490-1498. doi:10.1039/c3tb21821j

Robidillo, C. J. T., and Veinot, J. G. C. (2020). Functional Bio-Inorganic Hybrids from Silicon Quantum Dots and Biological Molecules. ACS Appl. Mater. Inter. 12, 52251-52270. doi:10.1021/acsami.0c14199

Schofield, C. L., Field, R. A., and Russell, D. A. (2007). Glyconanoparticles for the Colorimetric Detection of Cholera Toxin. Anal. Chem. 79 (4), 1356-1361. doi:10.1021/ac061462j

Schofield, C. L., Haines, A. H., Field, R. A., and Russell, D. A. (2006). Silver and Gold Glyconanoparticles for Colorimetric Bioassays. Langmuir 22 (15), 6707-6711. doi:10.1021/la060288r

Schofield, C. L., Marín, M. J., Rejzek, M., Crocker, P. R., Field, R. A., and Russell, D. A. (2016). Detection of mSiglec-E, in Solution and Expressed on the Surface of Chinese Hamster Ovary Cells, Using Sialic Acid Functionalised Gold Nanoparticles. Analyst 141 (20), 5799-5809. doi:10.1039/c6an01230b

Simpson, J., Craig, D., Faulds, K., and Graham, D. (2016). Mixed-monolayer Glyconanoparticles for the Detection of Cholera Toxin by Surface Enhanced Raman Spectroscopy. Nanoscale Horiz. 1 (1), 60-63. doi:10.1039/c5nh00036j

Sun, Q., Zhang, Y., Liu, M., Ye, Z., Yu, X., Xu, X., et al. (2019). Prognostic and Diagnostic Significance of Galectins in Pancreatic Cancer: a Systematic Review and Meta-Analysis. Cancer Cel Int 19 (1), 1-14. doi:10.1186/s12935-019-1025-5

Torres-Pérez, S. A., Torres-Pérez, C. E., Pedraza-Escalona, M., Pérez-Tapia, S. M., and Ramón-Gallegos, E. (2020). Glycosylated Nanoparticles for CancerTargeted Drug Delivery. Front. Oncol. 10, 1-10. doi:10.3389/fonc.2020.605037

Van Kasteren, S. I., Campbell, S. J., Serres, S., Anthony, D. C., Sibson, N. R., and Davis, B. G. (2009). Glyconanoparticles Allow Pre-symptomatic In Vivo
Imaging of Brain Disease. Proc. Natl. Acad. Sci. 106 (1), 18-23. doi:10.1073/ pnas.0806787106

Wang, L., Zhang, Y., He, H., Yang, H., and Wei, W. (2018). Simultaneous Quadruple-Channel Optical Transduction of a Nanosensor for Multiplexed Qualitative and Quantitative Analysis of Lectins. Chem. Commun. 54 (56), 7754-7757. doi:10.1039/C8CC02138D

Wang, N., Wei, X., Zheng, A.-Q., Yang, T., Chen, M.-L., and Wang, J.-H. (2017). Dual Functional Core-Shell Fluorescent Ag2S@Carbon Nanostructure for Selective Assay of E. coli O157:H7 and Bactericidal Treatment. ACS Sens. 2 (3), 371-378. doi:10.1021/acssensors.6b00688

Wang, X., Matei, E., Deng, L., Koharudin, L., Gronenborn, A. M., Ramström, O., et al. (2013). Sensing Lectin-Glycan Interactions Using Lectin Supermicroarrays and Glycans Labeled with Dye-Doped Silica Nanoparticles. Biosens. Bioelectron. 47, 258-264. doi:10.1016/j.bios.2013.03.014

Zhang, C., Shi, D.-T., Yan, K.-C., Sedgwick, A. C., Chen, G.-R., He, X.-P., et al. (2020). A Glycoconjugate-Based Gold Nanoparticle Approach for the Targeted Treatment of Pseudomonas aeruginosa Biofilms. Nanoscale 12 (45), 23234-23240. doi:10.1039/d0nr05365a

Zhang, H., Zhang, L., Liang, R.-P., Huang, J., and Qiu, J.-D. (2013). Simultaneous Determination of Concanavalin A and Peanut Agglutinin by Dual-Color Quantum Dots. Anal. Chem. 85 (22), 10969-10976. doi:10.1021/ac402496e

Zhang, Z., Qi, X., Chai, J., Wu, P., Lv, X., Cheng, S., et al. (2018). Detection of Glycan-Binding Proteins Using Glycan-Functionalized Quantum Dots and Gold Nanoparticles. J. Carbohydr. Chem. 37 (4), 199-209. doi:10.1080/ 07328303.2018.1451875

Zhang, Z., Schepens, B., Nuhn, L., Saelens, X., Schotsaert, M., Callewaert, N., et al. (2016). Influenza-binding Sialylated Polymer Coated Gold Nanoparticles Prepared via RAFT Polymerization and Reductive Amination. Chem. Commun. 52 (16), 3352-3355. doi:10.1039/c6cc00501b

Zheng, L., Wei, J., Lv, X., Bi, Y., Wu, P., Zhang, Z., et al. (2017). Detection and Differentiation of Influenza Viruses with Glycan-Functionalized Gold Nanoparticles. Biosens. Bioelectron. 91, 46-52. doi:10.1016/j.bios.2016.12.037

Conflict of Interest: Authors PH, SD, and RF were employed by the company Iceni Diagnostics Ltd. Iceni Diagnostics employs glyconanoparticles in diagnostic devices for virus detection.

The remaining author declares that the research was conducted in the absence of any commercial or financial relationships that could be construed as a potential conflict of interest.

Copyright $\odot 2021$ Hernando, Dedola, Marin and Field. This is an open-access article distributed under the terms of the Creative Commons Attribution License (CC BY). The use, distribution or reproduction in other forums is permitted, provided the original author(s) and the copyright owner(s) are credited and that the original publication in this journal is cited, in accordance with accepted academic practice. No use, distribution or reproduction is permitted which does not comply with these terms. 